\title{
Higher BNP levels within physiological range correlate with beneficial nonfasting lipid profiles in the elderly: a cross-sectional study
}

\author{
Wen-Tao He ${ }^{1,2}$, Masayuki Mori ${ }^{1}$, Xue-Feng $\mathrm{Yu}^{2}$ and Tsugiyasu Kanda ${ }^{1 *}$
}

\begin{abstract}
Background: Emerging studies indicate that B-type natriuretic peptide (BNP), a well-known biomarker for heart failure, also plays pivotal roles in metabolic control. Circulating BNP levels progressively increase as ages grow older. However, the association between BNP levels and lipid metabolism in the elderly remains unknown.

Methods: A total of 680 eligible volunteers (male/female: 334/346) aged between 60 and 80 years old without overt heart failure (BNP $<100 \mathrm{pg} / \mathrm{ml}$ ) were enrolled. Random nonfasting venous samples were obtained for biochemical analysis. The subjects were stratified based on BNP quartiles: BNP Q1 (range: 2.2-9.0 pg/ml), Q2 (9.1-20.4 pg/ml), Q3 (20.5-44.4 pg/ml) and Q4 (44.6-99.7 pg/ml). Difference of metabolic parameters was compared among the subjects grouped by BNP quartiles. Univariate correlation and multiple linear regression were performed to analyze the association between BNP levels and metabolic parameters. The odds ratios (OR) and $95 \%$ confidence intervals (Cl) for dyslipidemia in subjects within BNP Q1-3 relative to subjects within BNP Q4 were calculated.

Results: Circulating BNP levels positively correlated with age, while negatively correlated with body mass index (BMI), eGFR and non-HDL. Subjects with lower BNP quartiles had significantly elevated prevalence of dyslipidemia, including hypertriglyceridemia, hyper-LDL-emia and hypercholesterolemia. The OR of hypertriglyceridemia and hypercholesterolemia for subjects within BNP Q1-2 significantly increased relative to BNP Q4.
\end{abstract}

Conclusions: The elderly people with higher BNP levels have significantly reduced risks for nonfasting dyslipidemia. Verification of the cause-effect relationship between BNP and dyslipidemia may bring therapeutic implications.

Keywords: BNP, Nonfasting lipid profiles, The elderly, Dyslipidemia

\section{Background}

Natriuretic peptides (NPs) are a group of functionally and structurally related peptides, including atrial NP (ANP), B-type NP (BNP) and C-type NP (CNP). BNP is predominantly expressed by ventricular cells and correlates better with the severity of heart failure than ANP, so BNP has gained more intense researches as a clinically useful biomarker $[1,2]$.

\footnotetext{
* Correspondence: kandat@kanazawa-med.ac.jp

${ }^{1}$ Department of Community Medicine, Kanazawa Medical University Himi

Municipal Hospital, Himi, Toyama 935-8531, Japan

Full list of author information is available at the end of the article
}

Although higher BNP levels are often associated with adverse cardiovascular outcomes [3, 4], growing evidence has demonstrated that elevated BNP plays beneficial roles in metabolic regulation under non-heart failure settings. As opposed to cardiac cachexia partly mediated by raised $\mathrm{BNP}$ levels $[5,6]$, the inverse correlation between BNP and body mass index (BMI) has been consistently reported in a number of observational studies [7-9]. Mechanistically, BNP directly promotes mitochondrial biogenesis in skeletal muscles and white adipocytes to enhance energy expenditure [10, 11]. Through these mechanisms, transgenic mice 
overexpressed with BNP are highly resistant to high-fat diet induced obesity, insulin resistance and diabetes [10]. Thus, heart-derived BNP has been viewed as a central player in the control of body weight and energy metabolism.

Recently, it has been demonstrated that higher BNP levels correlate with favorable adiposity profiles, including reduced deposition of visceral and liver fat [12]. The pattern of body fat distribution is an independent factor associated with metabolic syndrome in the elderly population, including dyslipidemia [13]. Therefore, BNP might affect the lipid metabolism. Schlueter $\mathrm{N}$ et al. have postulated that BNP holds the potential to treat a series of metabolic disorders [14]. Paradoxically, existing data also suggest that higher BNP levels provide independently predictive value on assessment of future cardiovascular disease (CVD) risk [3], whereas cholesterollowering rosuvastatin treatment effectively improves the adverse outcome. In another study, a nonlinear $U$ relationship between BNP and metabolic syndrome has been observed [15]. It seems that the influence of BNP on CVD risks in clinic is far more complicated than experimental results from transgenic murine models. However, overexpression of BNP under cardiac stress belongs per se to a cluster of protectively compensatory events. Consequently, BNP to a certain extent benefits cardiac function through generalized loss of fat tissue in addition to natriuresis. Thus, high BNP levels might be associated with lipid metabolism. Nevertheless, the direct data available on this issue remain lacking.

We hypothesized that BNP might play beneficial roles in lipid metabolism. To this end, we investigated the associations between BNP levels and nonfasting lipid levels in the elderly people without overt heart failure. We found that the elderly people with higher BNP levels tended to have reduced prevalence of hypertriglyceridemia, hypercholesterolemia and hyper-LDL-emia, which supports the beneficial roles of BNP in lipid metabolism. This study was performed based on two major respects. Firstly, the elderly people have larger variation range of BNP levels than younger people [16], which might make the difference in lipid metabolism more visible. Secondly, emerging evidence supports the notion that nonfasting lipid levels provide more predictive values on risks for CVD than fasting lipids in additional to increased patient compliance. In several large populationbased prospectively observational studies, nonfasting triglyceride (TAG) has been shown to be a superior risk predictor for CVD compared with fasting TAG $[17,18]$. Nonfasting total cholesterol (TC), low-density lipoprotein cholesterol (LDL-C) and high-density lipoprotein cholesterol (HDL-C) change minimally in response to normal food intake [19].

\section{Methods}

\section{Study subjects}

All subjects who participated in the cross-sectional research were from community-dwelling residents received annual examinations in Himi Municipal Hospital, Kanazawa Medical University. From Jan 2012 to May 2015, a total of 1248 volunteers who met the following criteria were enrolled in the study. The inclusion criteria included: (1) age above 60 and less than 80 years old; (2) serum Cr levels less than $2 \mathrm{mg} / \mathrm{dL}$; (3) no overt dysfunction of heart, liver or lung diseases; (4) the level of BNP between 0 and $100 \mathrm{pg} / \mathrm{mL}$; (5) $0.1 \mathrm{mIU} / \mathrm{L} \leq \mathrm{TSH} \leq 10$ $\mathrm{mIU} / \mathrm{L}, \mathrm{FT} 3$ and FT4 within the normal range. As various factors affect the levels of BNP and lipids, such as acute inflammation, injury, thyroid hormones, blood volume and sex steroids, we excluded those who met the exclusion criteria, including: (1) acute infection and stress in the last three months $(n=59)$; (2) medication on lipid-lowering drugs, glucocortoids, sex steroids, diuretics and thyroid-related drugs $(n=413)$; (3) overt hyperthyroidism or hypothyroidism $(n=96)$. The remaining 680 participants were involved in this study. Electronic data on medical history for each participant are accessible in the computerized database of Himi Municipal Hospital. All participants provided informed written consent. The protocols of the study were approved by the Ethics Board of Kanazawa Medical University Himi Municipal Hospital (protocol number 34).

\section{Anthropometric measurements}

Anthropometric parameters obtained in this study included weight, height and BMI. BMI was calculated as body weight in kilograms divided by the height squared $\left(\mathrm{kg} / \mathrm{m}^{2}\right)$.

\section{Biochemical investigations}

Random venous blood samples were collected in tubes containing liquid EDTA and were centrifuged to obtain plasma for further biochemical analysis. Liver and kidney function tests, UA, TC, HDL-C, LDL-C and TAG were measured by automated analyzer (JCA-BM6050 Bio Majesty, Nihon Denshi Co. Ltd., Tokyo, Japan). The minimal detectable limit of BNP was $2.0 \mathrm{pg} / \mathrm{mL}$. The mean intra-assay and inter-assay coefficients were 2.1 and $3.6 \%$, respectively. Non-HDL was defined by the formula: non-HDL $=\mathrm{TC}-\mathrm{HDL}-\mathrm{C}$. HbA1c was examined by a latex coagulation method. BNP levels were measured using chemiluminescent enzyme immunoassay kit (MI02 Shionogi BNP; Shionogi Co. Ltd., Osaka, Japan). The serum thyroid function was measured by chemiluminescence assay. The eGFR was calculated by an equation for Japanese: eGFR $\left(\mathrm{ml} / \mathrm{min} / 1.73 \mathrm{~m}^{2}\right)=194 \times \mathrm{Cr}^{-}$ ${ }^{1.094} \times$ age $^{-0.287} \times 0.739$ (if female). Currently, there are no available age- and population-based standards for random 
lipid levels. Previous research has found that minimal difference exists between nonfasting and fasting lipid levels [19]. In this study, definition criteria for abnormal lipid metabolic indicators were used with reference to the following statement or guideline, including American Heart Association (AHA) scientific statement on triglycerides and CVD [17], and American Association of Clinical Endocrinologists' Guidelines for Management of Dyslipidemia and Prevention of Atherosclerosis (2012) [20]. Specifically, cut-off points for dyslipidemia were defined as any one of the following: $\mathrm{TC} \geq 200 \mathrm{mg} / \mathrm{dL}$, LDL$\mathrm{C} \geq 130 \mathrm{mg} / \mathrm{dL}, \mathrm{HDL}-\mathrm{C} \leq 60 \mathrm{mg} / \mathrm{dL}$ or $\mathrm{TAG} \geq 200 \mathrm{mg} / \mathrm{dL}$.

\section{Statistical analysis}

The study population was separated into four groups according to BNP quartiles, namely BNP Q1-Q4. The normality of distribution was performed by KolmogorovSmirnov test. Variables with skewed distribution were expressed as median and quartile ranges (25th to 75 th percentiles). Continuous variables with normal distribution were expressed as mean \pm standard deviation (SD). Categorical variables were expressed as numbers and percentages. Chi-square test was used to compare categorical variables. The difference of variables among different BNP categories was compared by One-Way ANOVA test, and then Student-Newman-Keuls pairwise comparisons were performed if $P<0.05$. Difference of BNP levels in subjects with normal and abnormal lipids was analyzed by Mann-Whitney $U$ test. Univariate association between BNP and continuous variables was expressed as Spearman's correlation coefficients. Values were transformed to the log base of 10 to obtain standard normal variables if needed. Stepwise multiple linear regression was used to correct the effects of covariates and to test the independent factors. Logistic regression was performed to estimate the OR and corresponding $95 \%$ CI for dyslipidemia. Data were analyzed by software SPSS version 16.0 (SPSS Inc., Chicago, IL, USA). P $<0.05$ (two-tailed) was considered to be statistically significant for all analysis.

\section{Results}

The clinical and biochemical characteristics of the study population

The clinical, biochemical and anthropometric characteristics of the study population stratified by BNP quartiles were summarized in Table 1 . The subjects were divided into four quartiles according to BNP levels (median values: $7.0,14.9,30.6$ and $65.5 \mathrm{pg} / \mathrm{ml}$, respectively). The prevalence of diabetes, hypertension, alcohol consumption and smoking was comparable among four groups. $\mathrm{TSH}$, aspartate aminotransferase (AST), gamma-glutamyl transpeptidase (GGT), eGFR, non-HDL and hemoglobin A1c (HbA1c). Compared to the highest BNP quartile
(Q4), the lower BNP quartile (Q1 and/or Q2) tended to have younger age, lower $\mathrm{Cr}$ and HDL-C, and higher alanine aminotransferase (ALT), BMI, TC, LDL-C and TAG $(P<0.05)$. The levels of UA followed a trend of biphasic alteration with the elevation of BNP quartiles. BNP Q3 had significantly lower levels of UA compared to BNP Q1 and Q4 $(P<0.05)$. These findings suggest that BNP levels correlate with age, ALT, Cr, BMI, TC, LDL-C, HDL-C, TAG and UA in this elderly population.

\section{Association between plasma BNP levels with clinical parameters}

Table 2 shows the association of clinical characteristics with plasma BNP levels by using univariable correlation and multiple linear regression analysis. BNP as the dependent variable was logarithmically transformed to approximate normal distribution. In univariable correlation, age was positively correlated with plasma BNP (Spearman's $\rho=0.361$ ), whereas ALT, GGT, eGFR, TC, TAG and non-HDL were negatively correlated with plasma BNP $(\rho=-0.327,-0.175,-0.117,-0.161,-0.184$ and -0.170 , respectively). In addition, BMI and LDL-C were negatively associated with plasma BNP with marginally statistical significance. After stepwise multiple regression adjusting for covariates (model $R^{2}=0.271$, $P<0.01$ ), age was still positively associated with plasma BNP $(\beta=0.051)$, whereas BMI, eGFR and non-HDL were inversely associated with plasma BNP $(\beta=-0.047$, -0.189 and -0.113 , respectively). The data indicate that BNP levels, in addition to age, BMI, non-HDL and eGFR, were significantly associated with nonfasting lipid parameters.

\section{Dyslipidemia prevalence in individuals with different BNP quartiles, and BNP levels in subjects with normal or abnormal lipid levels}

We next sought to explore the potential relationships between BNP levels and dyslipidemia. As shown in Fig. 1a, the prevalence of dyslipidemia gradually reduced with the increase of BNP levels, including high TC, high TAG and high LDL-C $\left({ }^{*}, P<0.01\right.$; $* *, P<0.001$; compared to BNP Q1). Figure 1b shows the BNP levels in normal and abnormal lipid groups. The medians of BNP were significantly lower in subjects with abnormal TC, LDL and TAG than those with normal respective lipids (*, $P$ $<0.01$; **, $P<0.001)$. These findings demonstrate that higher BNP levels negatively correlated with the prevalence of nonfasting dyslipidemia.

\section{Subjects with lower BNP quartiles (Q1-3) tend to have raised risks for nonfasting dyslipidemia compared to the highest BNP quartile (Q4)}

Adjusted odds ratios (OR) with associated $95 \%$ confidence intervals $(\mathrm{CI})$ of nonfasting dyslipidemia in the 
Table 1 Difference in clinical characteristics of the population stratified by BNP quartiles

\begin{tabular}{|c|c|c|c|c|c|}
\hline \multirow[t]{2}{*}{ Variables } & BNP Q1 & BNP Q2 & BNP Q3 & BNP Q4 & \multirow[t]{2}{*}{$P$ value } \\
\hline & $n=170$ & $n=170$ & $n=170$ & $n=170$ & \\
\hline Men, n (\%) & $101(59.4)$ & 72 (42.4) & 67 (39.4) & 94 (55.3) & $<0.0001^{a}$ \\
\hline Age, years & $68 \pm 5$ & $68 \pm 5$ & $69 \pm 6$ & $70 \pm 5$ & $0.015^{b}$ \\
\hline BNP, pg/ml & $7.0(5.5-8.0)$ & $14.9(11.2-17.3)$ & $30.6(24.3-37.4)$ & $65.5(53.9-83.5)$ & - \\
\hline BNP range, $\mathrm{pg} / \mathrm{ml}$ & $2.2-9.0$ & $9.1-20.4$ & $20.5-44.4$ & 44.6-99.7 & - \\
\hline $\mathrm{BMI}, \mathrm{kg} / \mathrm{m}^{2}$ & $23.4 \pm 4.1$ & $24.4 \pm 4.0$ & $23.1 \pm 4.3$ & $22.5 \pm 3.3$ & $0.017^{c}$ \\
\hline$A L T, I U / L$ & $28.5 \pm 19.7$ & $21.2 \pm 13.0$ & $18.9 \pm 11.5$ & $19.3 \pm 21.0$ & $<0.0001^{d}$ \\
\hline AST, IU/L & $27.0 \pm 14.8$ & $24.0 \pm 12.1$ & $22.5 \pm 10.1$ & $25.2 \pm 20.8$ & 0.232 \\
\hline GGT, IU/L & $45.6 \pm 58.0$ & $30.1 \pm 62.2$ & $32.9 \pm 48.6$ & $34.7 \pm 43.3$ & 0.259 \\
\hline$U A, m g / d L$ & $5.5 \pm 1.3$ & $5.2 \pm 1.4$ & $5.1 \pm 1.5$ & $5.5 \pm 1.6$ & $0.04^{e}$ \\
\hline $\mathrm{Cr}, \mathrm{mg} / \mathrm{dL}$ & $0.78 \pm 0.19$ & $0.74 \pm 0.18$ & $0.76 \pm 0.24$ & $0.81 \pm 0.25$ & $0.0334^{f}$ \\
\hline $\operatorname{eGFR}\left(\mathrm{ml} / \mathrm{min} / 1.73 \mathrm{~m}^{2}\right)$ & $74.3 \pm 25.9$ & $73.6 \pm 15.4$ & $73.1 \pm 19.9$ & $70.2 \pm 20.8$ & 0.1860 \\
\hline $\mathrm{TC}, \mathrm{mg} / \mathrm{dL}$ & $191.3 \pm 37.3$ & $200.1 \pm 38.7$ & $188.1 \pm 34.2$ & $179.6 \pm 38.6$ & $<0.0001^{\mathrm{g}}$ \\
\hline $\mathrm{LDL}-\mathrm{C}, \mathrm{mg} / \mathrm{dL}$ & $115.7 \pm 35.0$ & $119.0 \pm 37.0$ & $108.5 \pm 33.2$ & $107.4 \pm 33.7$ & $0.022^{h}$ \\
\hline $\mathrm{HDL}-\mathrm{C}, \mathrm{mg} / \mathrm{dL}$ & $49.1 \pm 11.5$ & $55.7 \pm 15.2$ & $53.6 \pm 13.8$ & $53.0 \pm 16.4$ & $0.003^{i}$ \\
\hline $\mathrm{TAG}, \mathrm{mg} / \mathrm{dL}^{※}$ & $147.0(107.3-223.0)$ & $131.0(91.75-184.0)$ & 116.0 (91.0-170.0) & $121.0(83.0-158.3)$ & $<0.0001^{j}$ \\
\hline non-HDL, mg/dL & $142.2 \pm 34.6$ & $143.5 \pm 37.1$ & $133.8 \pm 33.2$ & $125.9 \pm 33.3$ & 0.081 \\
\hline TSH, mIU/L ${ }^{※}$ & $1.6(1.1-3.2)$ & $1.5(0.9-2.4)$ & $1.5(1.1-2.3)$ & $1.5(0.9-2.9)$ & 0.714 \\
\hline $\mathrm{HbA} 1 \mathrm{c}, \%$ & $6.0 \pm 0.8$ & $6.1 \pm 1.3$ & $6.1 \pm 1.3$ & $6.0 \pm 1.1$ & 0.3629 \\
\hline Diabetes, n (\%) & $49(28.8)$ & $36(21.2)$ & $33(19.4)$ & $38(22.4)$ & 0.182 \\
\hline Hypertension, n (\%) & $118(69.4)$ & $109(64.1)$ & $113(66.5)$ & $121(71.2)$ & 0.516 \\
\hline Current Smoker, n (\%) & $25(14.7)$ & $15(8.8)$ & $16(9.4)$ & 18 (10.6) & 0.296 \\
\hline Current Drinker, n (\%) & $13(7.6)$ & $16(9.4)$ & $9(5.3)$ & $13(7.6)$ & 0.552 \\
\hline
\end{tabular}

Data are expressed as mean \pm SD for data with normal distribution, or median (25th, 75th percentiles) for data with skewed distribution, or number (percentage) for categorical data. Chi-square test was used to compare categorical variables. The difference of continuous variables was compared using One-Way ANOVA, and then Student-Newman-Keuls pairwise comparisons were performed if $P<0.05$. $P$ values less than 0.05 are marked in bold. Note: (1) $※$ Analysis was performed using log-transformed data. (2) a. Q1 compared with Q2 and Q3 $(P=0.002,<0.0001)$; Q4 compare with Q2 and Q3 $(P=0.0017,0.003)$; b. Q4 compared with Q1, Q2 and Q3 $(P=0.03,0.008,0.073)$; c. Q2 compared with Q3 and Q4 $(P=0.027,0.002)$; d. Q1 compared with Q2, Q3 and Q4 $(P=0.006,<0.0001$, $<0.0001)$; e. Q3 compared with Q1 and Q4 $(P=0.025,0.016) ; f$. Q4 VS Q2, $P<0.05 ; \mathrm{g}$. Q2 compared with Q3 and Q4 $(P=0.010,<0.0001)$; Q1 compared with Q4 $(P=0.015)$; h. Q2 compared with Q3 and Q4 $(P=0.016,0.009)$; i. Q1 compared with Q2, Q3 and Q4 $(P<0.0001,0.013,0.036)$; j. Q1 compared with Q2, Q3 and Q4 $(P=0.006,<0.0001,<0.0001)$

BNP Q1-3 were shown in Fig. 2, with BNP Q4 as reference. In model 1 (adjusted for smoking, hypertension, drinking, diabetes, HbA1c, TSH, ALT, AST, GGT and UA), the risks of hypercholesterolemia, hyper-LDL-emia and hypertriglyceridemia were significantly elevated in the BNP Q1 group, while the risks for hypertriglyceridemia was progressively reduced in BNP Q2 and Q3 group. In model 2 (additionally adjusted for eGFR) and model 3 (further adjustment for age and BMI), the results were similar to model 1 . In model 3 , individuals in the BNP Q1 and Q2 quartiles had increased risks for nonfasting dyslipidemia (OR [95 \% CI] for BNP Q1: TC 2.042 [1.192-3.500], $P=0.009 ; \mathrm{Q} 2: \mathrm{TC}$ $2.316[1.372-3.911], P=0.002 ;$ BNP Q1: TAG 3.938 [2.013-7.702], $P<0.0001 ; \quad Q 2:$ TAG 2.134 [1.0514.336], $P=0.036)$. The OR for hyper-LDL-emia in the BNP Q1 quartile reached marginally statistical significance (OR [95 \% CI]: 1.778 [0.986-3.203], $P=0.056$ ).
These findings showed that subjects with higher BNP levels tended to have reduced risks for nonfasting dyslipidemia, especially for hypercholesterolemia and hypertriglyceridemia.

\section{Discussion}

In this cross-sectional study, we found that nonfasting dyslipidemia in the elderly Japanese population negatively correlated with BNP levels within the physiological range. The elderly people with the lowest BNP quartile were prone to have obviously elevated risks for nonfasting hypercholesterolemia and hypertriglyceridemia, as opposed to subjects with higher BNP quartiles. Although the correlation between BNP and lipid profiles was found but was not potent enough in linear analysis model, results from multiple regression analysis further supported this association independent of several clinical variables. 
Table 2 Linear and multiple regression analysis of association between metabolic parameters and BNP levels (Log BNP) in the subjects

\begin{tabular}{|c|c|c|c|c|}
\hline \multirow[t]{2}{*}{ Variables } & \multicolumn{2}{|c|}{ Univariate correlation } & \multicolumn{2}{|c|}{ Multivariate regression } \\
\hline & $\rho$ coefficient & $P$ value & $\beta$ coefficient & $P$ value \\
\hline Gender (men,1; women, 0) & -0.028 & 0.602 & & \\
\hline Age (years) & 0.361 & $<0.001$ & 0.051 & $<0.001$ \\
\hline BMI $\left(\mathrm{kg} / \mathrm{m}^{2}\right)$ & -0.128 & 0.054 & -0.047 & 0.001 \\
\hline ALT (IU/L) & -0.327 & $<0.001$ & & \\
\hline AST (IU/L) & -0.089 & 0.093 & & \\
\hline GGT (IU/L) & -0.175 & 0.001 & & \\
\hline UA (mg/dL) & 0.035 & 0.563 & & \\
\hline $\operatorname{Cr}(\mathrm{mg} / \mathrm{dL})$ & 0.054 & 0.306 & & \\
\hline eGFR (ml/min/1.73 m²) & -0.117 & 0.027 & -0.189 & 0.005 \\
\hline $\mathrm{TC}(\mathrm{mg} / \mathrm{dL})$ & -0.161 & 0.007 & & \\
\hline LDL-C (mg/dL) & -0.119 & 0.054 & & \\
\hline $\mathrm{HDL}-\mathrm{C}(\mathrm{mg} / \mathrm{dL})$ & 0.050 & 0.403 & & \\
\hline Log TAG (mg/dL) & -0.184 & 0.001 & & \\
\hline non-HDL (mg/dL) & -0.170 & 0.008 & -0.113 & $<0.001$ \\
\hline Log TSH (mIU/L) & -0.021 & 0.650 & & \\
\hline $\mathrm{HbA1c}(\%)$ & 0.125 & 0.321 & & \\
\hline Diabetes (yes $=1 ; \mathrm{no}=0$ ) & -0.045 & 0.481 & & \\
\hline Hypertension (yes $=1 ;$ no $=0$ ) & 0.012 & 0.621 & & \\
\hline Smoking (yes = $1 ;$ no $=0$ ) & 0.008 & 0.724 & & \\
\hline Drinking (yes $=1 ; \mathrm{no}=0$ ) & 0.005 & 0.565 & & \\
\hline
\end{tabular}

$P$ values less than 0.05 are marked in bold

$\mathrm{N}$-terminal of the prohormone brain natriuretic peptide (NT-proBNP) which is equimolarly released into circulation with BNP, has also been used widely as a surrogate biomarker for BNP. Recently, the levels of fasting LDL-C and TAG have been demonstrated to be inversely associated with NT-proBNP and followed a biphasic pattern, with the turning point at $100 \mathrm{pg} / \mathrm{ml}$ [21]. The linear associations between lipids and NT-proBNP became not obvious for those whose NT-proBNP levels were higher than $100 \mathrm{pg} / \mathrm{ml}$. This study also established a positive correlation of HDL-C level with NT-proBNP, which is a little different from our results. Although the linear trend between HDL-C and BNP was not observed in the current population, subjects with BNP Q1 had markedly
A

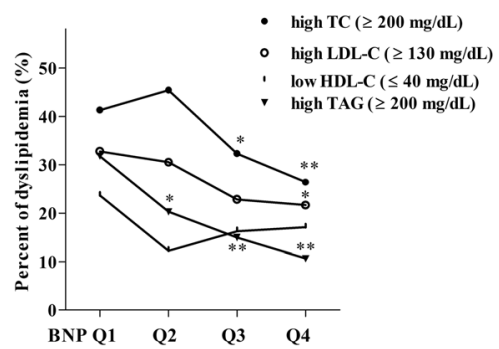

B

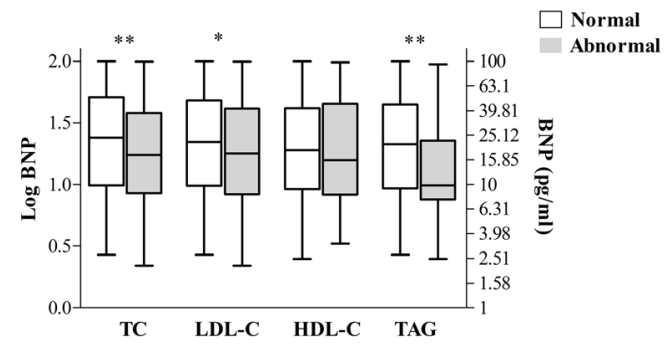

Fig. 1 a The prevalence of abnormal lipid profiles stratified by different BNP quartiles (*, $P<0.01$ vs. Q1; ${ }^{* *}, P<0.001$ vs. Q1). The cut-off points of dyslipidemia were defined as described in the methods. Chi-square test was used to compare the difference. $\mathbf{b}$ The difference of BNP levels between normal and abnormal groups according to lipid profiles. The lines denote the median, the boxes represent interquartile range, and the bars indicate the lowest or highest BNP levels. Boxes in grey denote patients with abnormal lipid profiles, whereas open boxes represent patients with normal lipid profiles (Mann-Whitney $U$ test was used. ${ }^{*}, P<0.01$ vs. normal group; ${ }^{*}, P<0.001$ vs. normal group). Note that numbers on the right vertical axis are corresponding to log-transformed values on the left axis 

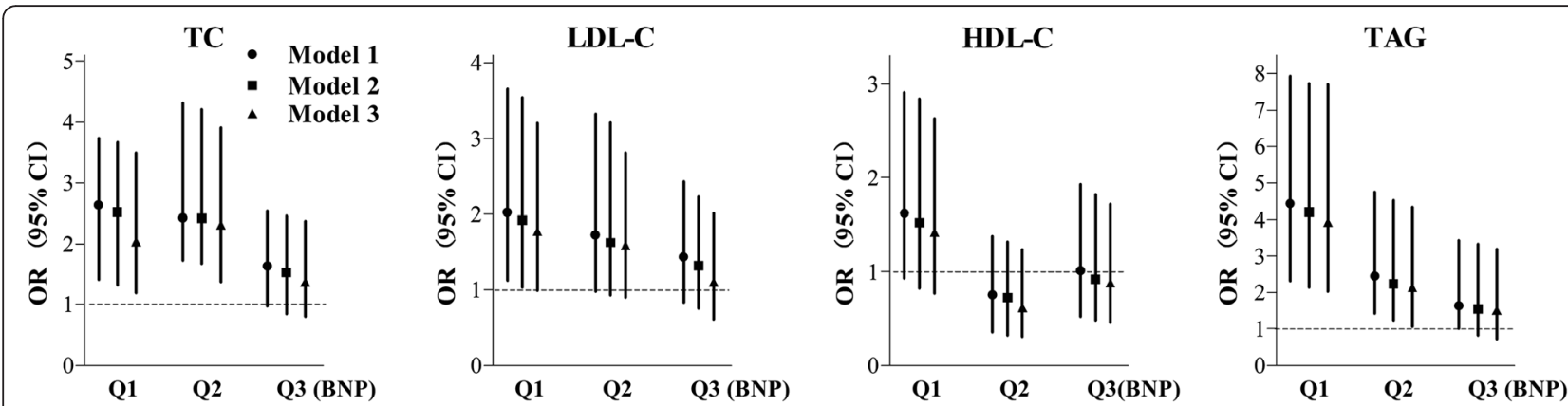

Fig. 2 Logistic regression to evaluate the OR and $95 \%$ Cl for dyslipidemia in BNP quartiles (Q1, Q2, Q3) compared to BNP Q4. Model 1: adjusted for smoking, hypertension, drinking, diabetes, HbA1C, TSH, ALT, AST, GGT and UA; Model 2: Model $1+$ eGFR; Model 3: Model $2+$ age + BMI

reduced HDL-C than subjects with BNP Q2-4 (Table 1). Nevertheless, both studies have consistently confirmed increased risks of dyslipidemia for individuals with low BNP levels regardless of the ethnicity or fasting status.

The mechanisms for the association between BNP levels and lipid metabolism can be ascribed to several reasons. BNP levels are determined by the dynamic balance of production and clearance. Firstly, several humoral factors are involved in the modulation of BNP secretion, including glucagon-like peptide-1 (GLP-1) [1] GLP-1 is well-recognized as an intestinal hormone with significantly reduced levels in obese patients [22]. GLP-1 directly promotes the secretion of ANP in atrial cardiomyocytes through GLP-1 receptor [23]. Although it remains unknown whether the similar phenomenon exists in BNP secretion, another clinical study observed that ANP and BNP both were elevated after GLP-1 analogue treatment [24]. Chronic inflammation triggered by relative adipocyte hypoxia is a hallmark in metabolic disorders [25]. As a well-known factor involved in insulin resistance, tumor necrosis factor- $\alpha$ (TNF- $\alpha$ ) also impairs GLP-1 secretion from the intestinal L-cells [26]. This is in accord with the clinical observation that patients with fatty liver disease or obesity have low levels of GLP-1 $[27,28]$. Secondly, plasma BNP is cleared through receptor-mediated degradation and extracellular proteasedependent pathways. Natriuretic peptide clearance receptor (NPR-C) is a pseudo-receptor which binds the BNP for internalization and degradation. Increased NPR-C in the adipose tissue accelerates the clearance of BNP in the obese individuals $[29,30]$. In addition, insulin-degrading enzyme (IDE) and dipeptidyl peptidase-4 (DPP-4) have been demonstrated to inactivate BNP in a proteasedependent manner $[31,32]$. Recently, it has been shown that the activity of IDE in the liver is enhanced in a dietinduced obesity model [33]. DPP-4 hyperactivity has been observed in morbidly obese patients [34, 35]. Thus, multiple mechanisms are responsible for the BNP handicap phenomenon in metabolic syndrome. Thirdly, BNP is dependent on renal function for clearance [36]. So, it is reasonable that age-dependent $\mathrm{BNP}$ elevation may be partly due to the decline of eGFR with aging. The agerelated elevation of BNP might be a protective mechanism for favorable lipid metabolism. The U-shaped alteration of UA levels from the lowest to highest BNP quartiles (Q1-Q4) may be the consequence of reduced metabolic syndrome together with elevated eGFR.

In our study, subjects within BNP Q1 had higher ALT levels than individuals with BNP Q2-4, which may be caused by increased prevalence of fatty liver diseases. Similarly, the mean BMI in BNP Q2 group was markedly higher than BNP Q3-4. From the observation that BNP is inversely related with visceral fat and liver fat [12], we may extrapolate that high prevalence of metabolic hepatic abnormalities and dyslipidemia in people with low levels of BNP are in part caused by ectopic fat accumulation. Interestingly, BNP also functions to increase the feeling of satiety. People with low levels of BNP are predisposed to have increased appetite which results in obesity [37]. Higher ALT and insulin resistance have long been considered as a risk factor for high TAG levels [38]. In addition, BNP levels have been shown to be negatively correlated with insulin resistance irrespective of obesity [39]. Insulin resistance in the liver not only promotes the de novo hepatic lipogenesis but also reduces the degradation of TAG-enriched lipoproteins, leading to both fasting and postprandial hypertriglyceridemia [40]. Insulin sensitivity index has repeatedly been documented to be associated with increased cholesterol synthesis in a hyperglycemia-independent manner $[41,42]$.

Traditionally, lipid levels have been determined in the fasting state mainly due to the reduced variability than random sampling. The evidences from a large number of epidemiological studies repeatedly support the riskpredictive values of nonfasting lipids, especially nonfasting TAG, for CVD [18]. Individuals with hyperglyceridemia are prone to produce strongly atherogenic lipoproteins, such as cholesterol-rich remnant-like lipoproteins and small dense LDL particles [43]. The finding 
in this study that significantly higher prevalence of hyperglyceridemia links with the lowest BNP Q1 quartile $(2.2-9.9 \mathrm{pg} / \mathrm{ml})$ is consistent with another recently published observation [21]. Therefore, individuals with lower BNP levels may have increased risk for CVD events regardless of the races, age, gender and BMI. As mentioned earlier, higher levels of BNP correlates with increased vascular events and all-cause mortality in Justification for the Use of Statins in Prevention: An Intervention Trial Evaluating Rosuvastatin (JUPITER) [3], which is inconsistent with our observation. This discrepancy might be caused by the eligible participants involved in JUPITER who had LDL-C $<130 \mathrm{mg} / \mathrm{dL}$. Therefore, the study has excluded people with lower BNP levels which often link with dyslipidemia. It should be acknowledged that people with higher BNP often have increased risks for cardiovascular events, which includes older age, myocardial injuries and elevated eGFR. Thus, our study doesn't imply that higher BNP correlates with better clinical outcome.

However, several limitations exist in our current study. Firstly, data on waist circumference which reflect visceral obesity are lacking. Secondly, insulin resistance which is a predisposing factor for dyslipidemia may be associated with BNP levels. The insulin resistance index and glucose metabolism are unknown in the study. Thirdly, our cross-sectional observation is unable to establish potential cause-effect relationship between BNP levels and dyslipidemia. In addition, the sample size of the population is not large enough. Thus, our findings require further studies to identify the relationship between plasma BNP levels and lipid profiles.

\section{Conclusions}

In conclusion, the current cross-sectional study provides further evidence about the metabolic risks of low BNP levels in the elderly. Elderly individuals with lower BNP levels tend to have higher prevalence of nonfasting dyslipidemia. Thus, it warrants further investigation whether BNP could serve as a biomarker or have therapeutic implications for dyslipidemia in the elderly people.

\footnotetext{
Abbreviations

ANP: atrial natriuretic peptide; BNP: B-type natriuretic peptide; CNP: C-type natriuretic peptide; BMI: body mass index; CVD: cardiovascular diseases; TAG: triglyceride; TC: total cholesterol; LDL-C: low-density lipoprotein cholesterol; HDL-C: high-density lipoprotein cholesterol; TSH: thyroid stimulating hormone; AST: aspartate aminotransferase; GGT: gamma-glutamyl transpeptidase; eGFR: estimated glomerular filtration rate; HbA1c: hemoglobin A1c; Cr: creatinine; ALT: alanine aminotransferase; UA: uric acid; OR: odds ratios; $\mathrm{Cl}$ : confidence intervals; NT-proBNP: N-terminal of the prohormone brain natriuretic peptide; GLP-1: glucagon-like peptide-1; TNF-a: tumor necrosis factor-a; NPR-C: natriuretic peptide clearance receptor; IDE: insulin-degrading enzyme; DPP-4: dipeptidyl peptidase-4; JUPITER: justification for the use of statins in prevention: an intervention trial evaluating rosuvastatin; SD: standard deviation; ANOVA: analysis of variance.
}

\section{Competing interests}

The authors declare that they have no competing interests.

\section{Authors' contributions}

WH contributed to data collection, statistical analysis and wrote the manuscript; MM participated in data collection; XY participated in data interpretation; TK designed the research and revised the manuscript. All authors have read and approved the final version of the manuscript.

\section{Acknowledgements}

We are grateful to Dr. Du Ting-Ting for critical reading the manuscript. We also thank the colleagues in Kanazawa Medical University Himi Municipal Hospital for their collaboration on the study.

\section{Author details}

'Department of Community Medicine, Kanazawa Medical University Himi Municipal Hospital, Himi, Toyama 935-8531, Japan. ${ }^{2}$ Department of Endocrinology, Tongji Hospital, Tongji Medical College, Huazhong University of Science and Technology, Wuhan 430030, China.

Received: 17 October 2015 Accepted: 22 December 2015

\section{References}

1. Gruden G, Landi A, Bruno G. Natriuretic peptides, heart, and adipose tissue: new findings and future developments for diabetes research. Diabetes Care. 2014;37:2899-908

2. Abassi Z, Karram T, Ellaham S, Winaver J, Hoffman A. Implications of the natriuretic peptide system in the pathogenesis of heart failure: diagnostic and therapeutic importance. Pharmacol Ther. 2004;102:223-41.

3. Everett BM, Zeller T, Glynn RJ, Ridker PM, Blankenberg S. High-sensitivity cardiac troponin I and B-type natriuretic Peptide as predictors of vascular events in primary prevention: impact of statin therapy. Circulation. 2015;131:1851-60.

4. Mishra RK, Beatty AL, Jaganath R, Regan M, Wu AH, Whooley MA. B-type natriuretic peptides for the prediction of cardiovascular events in patients with stable coronary heart disease: the Heart and Soul Study. J Am Heart Assoc. 2014, 3

5. Polak J, Kotrc M, Wedellova Z, Jabor A, Malek I, Kautzner J, et al. Lipolytic effects of B-type natriuretic peptide 1-32 in adipose tissue of heart failure patients compared with healthy controls. J Am Coll Cardiol. 2011;58:1119-25.

6. Vaz Perez A, Doehner W, von Haehling S, Schmidt H, Zimmermann AV, Volk $H D$, et al. The relationship between tumor necrosis factor-alpha, brain natriuretic peptide and atrial natriuretic peptide in patients with chronic heart failure. Int J Cardiol. 2010;141:39-43.

7. Arora P, Reingold J, Baggish A, Guanaga DP, Wu C, Ghorbani A, et al. Weight loss, saline loading, and the natriuretic peptide system. J Am Heart Assoc. 2015;4:e001265.

8. Wang TJ, Larson MG, Levy D, Benjamin EJ, Leip EP, Wilson PW, et al. Impact of obesity on plasma natriuretic peptide levels. Circulation. 2004;109:594-600.

9. Daniels LB, Clopton P, Bhalla V, Krishnaswamy P, Nowak RM, McCord J, et al. How obesity affects the cut-points for B-type natriuretic peptide in the diagnosis of acute heart failure. Results from the Breathing Not Properly Multinational Study. Am Heart J. 2006;151:999-1005.

10. Miyashita K, Itoh $\mathrm{H}$, Tsujimoto $\mathrm{H}$, Tamura $\mathrm{N}$, Fukunaga $\mathrm{Y}$, Sone $\mathrm{M}$, et al. Natriuretic peptides/cGMP/cGMP-dependent protein kinase cascades promote muscle mitochondrial biogenesis and prevent obesity. Diabetes. 2009;58:2880-92.

11. Bordicchia M, Liu D, Amri EZ, Ailhaud G, Dessi-Fulgheri P, Zhang C, et al. Cardiac natriuretic peptides act via p38 MAPK to induce the brown fat thermogenic program in mouse and human adipocytes. J Clin Invest. 2012; 122:1022-36.

12. Neeland IJ, Winders BR, Ayers CR, Das SR, Chang AY, Berry JD, et al. Higher natriuretic peptide levels associate with a favorable adipose tissue distribution profile. J Am Coll Cardiol. 2013;62:752-60.

13. Goodpaster BH, Krishnaswami S, Harris TB, Katsiaras A, Kritchevsky SB, Simonsick EM, et al. Obesity, regional body fat distribution, and the metabolic syndrome in older men and women. Arch Intern Med. 2005;165:777-83.

14. Schlueter N, de Sterke A, Willmes DM, Spranger J, Jordan J, Birkenfeld AL. Metabolic actions of natriuretic peptides and therapeutic potential in the metabolic syndrome. Pharmacol Ther. 2014;144:12-27. 
15. Musani SK, Vasan RS, Bidulescu A, Liu J, Xanthakis V, Sims M, et al. Aldosterone, C-reactive protein, and plasma B-type natriuretic peptide are associated with the development of metabolic syndrome and longitudinal changes in metabolic syndrome components: findings from the Jackson Heart Study. Diabetes Care. 2013;36:3084-92.

16. Keyzer JM, Hoffmann JJ, Ringoir L, Nabbe KC, Widdershoven JW, Pop VJ. Age- and gender-specific brain natriuretic peptide (BNP) reference ranges in primary care. Clin Chem Lab Med. 2014;52:1341-6.

17. Miller M, Stone NJ, Ballantyne C, Bittner V, Criqui MH, Ginsberg HN, et al. Triglycerides and cardiovascular disease: a scientific statement from the American Heart Association. Circulation. 2011;123:2292-333.

18. Kolovou GD, Mikhailidis DP, Kovar J, Lairon D, Nordestgaard BG, Ooi TC, et al. Assessment and clinical relevance of non-fasting and postprandial triglycerides: an expert panel statement. Curr Vasc Pharmacol. 2011;9:258-70.

19. Langsted A, Freiberg JJ, Nordestgaard BG. Fasting and nonfasting lipid levels: influence of normal food intake on lipids, lipoproteins, apolipoproteins, and cardiovascular risk prediction. Circulation. 2008;118:2047-56

20. Jellinger PS, Smith DA, Mehta AE, Ganda O, Handelsman Y, Rodbard HW, et al. American Association of Clinical Endocrinologists' Guidelines for Management of Dyslipidemia and Prevention of Atherosclerosis. Endocr Pract. 2012;18 Suppl 1:1-78.

21. Sanchez OA, Duprez DA, Bahrami H, Daniels LB, Folsom AR, Lima JA, et al. The associations between metabolic variables and NT-proBNP are blunted at pathological ranges: the Multi-Ethnic Study of Atherosclerosis. Metabolism. 2014;63:475-83.

22. de Luis DA, Aller R, Conde R, Primo D, Izaola O, Castro MJ, et al. Basal glucagonlike peptide 1 levels and metabolic syndrome in obese patients. J Investig Med. 2012;60:874-7.

23. Kim M, Platt MJ, Shibasaki T, Quaggin SE, Backx PH, Seino S, et al. GLP-1 receptor activation and Epac2 link atrial natriuretic peptide secretion to control of blood pressure. Nat Med. 2013;19:567-75.

24. Li CJ, Yu Q, Yu P, Yu TL, Zhang QM, Lu S, et al. Changes in liraglutideinduced body composition are related to modifications in plasma cardiac natriuretic peptides levels in obese type 2 diabetic patients. Cardiovasc Diabetol. 2014:13:36.

25. Lee YS, Kim JW, Osborne O, da Oh Y, Sasik R, Schenk S, et al. Increased adipocyte $\mathrm{O} 2$ consumption triggers HIF-1alpha, causing inflammation and insulin resistance in obesity. Cell. 2014;157:1339-52.

26. Gagnon J, Sauve M, Zhao W, Stacey HM, Wiber SC, Bolz SS, et al. Chronic Exposure to TNFalpha Impairs Secretion of Glucagon-Like Peptide-1. Endocrinology. 2015;156:3950-60.

27. Faerch K, Torekov SS, Vistisen D, Johansen NB, Witte DR, Jonsson A, et al. GLP-1 Response to Oral Glucose Is Reduced in Prediabetes, Screen-Detected Type 2 Diabetes, and Obesity and Influenced by Sex: The ADDITION-PRO Study. Diabetes. 2015;64:2513-25

28. Bernsmeier C, Meyer-Gerspach AC, Blaser LS, Jeker L, Steinert RE, Heim MH, et al. Glucose-induced glucagon-like Peptide 1 secretion is deficient in patients with non-alcoholic fatty liver disease. PLoS One. 2014;9:e87488.

29. Das SR, Drazner MH, Dries DL, Vega GL, Stanek HG, Abdullah SM, et al. Impact of body mass and body composition on circulating levels of natriuretic peptides: results from the Dallas Heart Study. Circulation. 2005:112:2163-8.

30. Sarzani R, Strazzullo P, Salvi F, lacone R, Pietrucci F, Siani A, et al. Natriuretic peptide clearance receptor alleles and susceptibility to abdominal adiposity. Obes Res. 2004;12:351-6.

31. Ralat LA, Guo Q, Ren M, Funke T, Dickey DM, Potter LR, et al. Insulindegrading enzyme modulates the natriuretic peptide-mediated signaling response. J Biol Chem. 2011;286:4670-9.

32. dos Santos L, Salles TA, Arruda-Junior DF, Campos LC, Pereira AC, Barreto $A L$, et al. Circulating dipeptidyl peptidase IV activity correlates with cardiac dysfunction in human and experimental heart failure. Circ Heart Fail. 2013;6:1029-38

33. Wei X, Ke B, Zhao Z, Ye X, Gao Z, Ye J. Regulation of insulin degrading enzyme activity by obesity-associated factors and pioglitazone in liver of diet-induced obese mice. PLoS One. 2014:9:e95399.

34. Stengel A, Goebel-Stengel M, Teuffel P, Hofmann T, Busse P, Kobelt P, et al. Obese patients have higher circulating protein levels of dipeptidy peptidase IV. Peptides. 2014;61:75-82.

35. Lugari R, Dei Cas A, Ugolotti D, Barilli AL, Camellini C, Ganzerla GC, et al. Glucagon-like peptide 1 (GLP-1) secretion and plasma dipeptidyl peptidase
IV (DPP-IV) activity in morbidly obese patients undergoing biliopancreatic diversion. Horm Metab Res. 2004;36:111-5.

36. van Kimmenade RR, Januzzi Jr JL, Bakker JA, Houben AJ, Rennenberg R, Kroon AA, et al. Renal clearance of B-type natriuretic peptide and amino terminal pro-B-type natriuretic peptide a mechanistic study in hypertensive subjects. J Am Coll Cardiol. 2009:53:884-90.

37. Vila G, Grimm G, Resl M, Heinisch B, Einwallner E, Esterbauer H, et al. B-type natriuretic peptide modulates ghrelin, hunger, and satiety in healthy men. Diabetes. 2012;61:2592-6.

38. Chiang JK, Lai NS, Chang JK, Koo M. Predicting insulin resistance using the triglyceride-to-high-density lipoprotein cholesterol ratio in Taiwanese adults. Cardiovasc Diabetol. 2011;10:93.

39. Khan AM, Cheng S, Magnusson M, Larson MG, Newton-Cheh C, McCabe EL, et al. Cardiac natriuretic peptides, obesity, and insulin resistance: evidence from two community-based studies. J Clin Endocrinol Metab. 2011;96:3242-9.

40. Ginsberg HN, Zhang YL, Hernandez-Ono A. Regulation of plasma triglycerides in insulin resistance and diabetes. Arch Med Res. 2005:36:232-40.

41. Gylling H, Hallikainen M, Pihlajamaki J, Simonen P, Kuusisto J, Laakso M, et al. Insulin sensitivity regulates cholesterol metabolism to a greater extent than obesity: lessons from the METSIM Study. J Lipid Res. 2010;51:2422-7.

42. Pihlajamaki J, Gylling H, Miettinen TA, Laakso M. Insulin resistance is associated with increased cholesterol synthesis and decreased cholesterol absorption in normoglycemic men. J Lipid Res. 2004;45:507-12.

43. Stalenhoef AF, de Graaf J. Association of fasting and nonfasting serum triglycerides with cardiovascular disease and the role of remnant-like lipoproteins and small dense LDL. Curr Opin Lipidol. 2008:19:355-61.

44. Fox ER, Musani SK, Bidulescu A, Nagarajarao HS, Samdarshi TE, Gebreab SY, et al. Relation of obesity to circulating B-type natriuretic peptide concentrations in blacks: the Jackson Heart Study. Circulation. 2011;124:1021-7.

\section{Submit your next manuscript to BioMed Central and we will help you at every step:}

- We accept pre-submission inquiries

- Our selector tool helps you to find the most relevant journal

- We provide round the clock customer support

- Convenient online submission

- Thorough peer review

- Inclusion in PubMed and all major indexing services

- Maximum visibility for your research

Submit your manuscript at www.biomedcentral.com/submit

) Biomed Central 